\title{
Effect of oral aminophylline in patients with angina and normal coronary arteriograms (cardiac syndrome $\mathrm{X}$ )
}

Perry M Elliott, Katarzyna Krzyzowska-Dickinson, Ramon Calvino, Carole Hann, Juan Carlos Kaski

\begin{abstract}
Background-Patients with syndrome $\mathbf{X}$ (exertional angina, positive exercise test, normal coronary arteriogram) have an altered perception of cardiac pain. This symptom may arise from increased sensitivity to adenosine. Previous studies suggest that intravenous aminophylline (an adenosine receptor blocker) improves exercise tolerance in patients with this disorder.
\end{abstract}

Objective-To examine the efficacy of oral aminophylline in syndrome $X$.

Methods-13 patients (11 women and two men, mean (SD) 54 (6) years) with syndrome $X$ were studied. Patients were randomised in a double blind crossover study to receive either oral aminophylline or placebo for three weeks. All patients underwent symptom limited exercise testing and ambulatory electrocardiography at the end of each three week period. Results-10 patients completed the study. The time to angina during exercise testing in patients who were given aminophylline was longer than for the placebo group (mean (SD) 632 (202) seconds $v 522$ (264) seconds, $P=0.004)$. Peak exercise ST depression did not differ significantly between patients who received aminophylline and those administered placebo (mean (SD) $-1.9(0.7) \mathrm{mm} v-1.5(0.8)$ mm). Six patients taking aminophylline reported a reduction in the total number of episodes of chest pain during the three weeks, but the frequency and duration of ST segment depression during Holter monitoring was unchanged.

Conclusion-Oral aminophylline has a favourable effect on exercise induced chest pain threshold in patients with syndrome $X$. The disparate effects on symptoms and ST segment changes are intriguing and further study is warranted.

St George's Hospital Medical School, London, United Kingdom

P M Elliott

K Krzyzowska-Dickinson

R Calvino

C Hann

J C Kaski

Correspondence to:

Dr Kaski, Department of Cardiological Sciences, $\mathrm{St}$ George's Hospital Medical School, Cranmer Terrace, London SW 17 ORE, United Kingdom.

Accepted for publication 3 March 1997

The term syndrome $\mathrm{X}$ describes patients who have typical exertional chest pain and exercise induced ST segment depression despite angiographically normal coronary arteries. ${ }^{1}$ Blunted coronary vasodilator reserve in some patients with the syndrome ${ }^{2-4}$ inspired the hypothesis that myocardial ischaemia, caused by "microvascular angina", is the underlying cause of chest pain. ${ }^{5}$ Disparate findings of subsequent studies examining coronary blood flow in patients with syndrome $\mathrm{X}^{6}$ and the fact that myocardial ischaemia can be documented in only a small proportion of patients, ${ }^{7}$ however, indicate that other mechanisms may be responsible for the genesis of chest pain. Altered somatic and visceral pain perception $^{8-11}$ in some patients with angina and normal coronary arteriograms suggests that chest pain is secondary to heightened cardiac pain sensitivity. The nature of the putative sensory abnormality in syndrome $\mathrm{X}$ is unknown, but abnormal myocardial sensitivity to algogenic substances may be responsible. ${ }^{12}$ Of the suggested pain mediators, adenosine is of particular interest, as in addition to its algogenic properties, it has a major role in regulating microvascular blood flow that could explain other aspects of syndrome $\mathrm{X}$ pathophysiology. ${ }^{13}$ Aminophylline (a competitive inhibitor of adenosine pruinergic receptors) in patients with coronary artery disease raises ischaemic threshold and improves exercise tolerance. ${ }^{14} 15$ Similar findings have been observed in patients with syndrome $\mathrm{X}$ following short term intravenous administration of aminophylline, ${ }^{16-18}$ but the clinical efficacy of chronic oral treatment has not been examined.

\section{Methods \\ PATIENTS}

Thirteen patients (11 women and two men, mean (SD) age 54 (6) years, range 47 to 64 ) with syndrome $\mathrm{X}$ were studied. All patients had a history of typical angina pectoris, mainly or exclusively on effort, and a positive electrocardiographic response during exercise. None of the patients had diabetes mellitus, systemic hypertension (defined as a blood pressure of $150 / 90 \mathrm{~mm} \mathrm{Hg}$ on at least three occasions over three months), or a history of prior myocardial infarction. No patient had Prinzmetal's variant angina, and coronary artery spasm was excluded by hyperventilation and ergonovine provocation tests. There was no history of asthma or chronic obstructive airways disease. Mean (SD) plasma cholesterol was 6.1 (0.9) $\mathrm{mmol} / \mathrm{l}$, range $5 \cdot 3-7 \cdot 5$. Baseline resting 12

lead electrocardiograms were normal. Conventional cross sectional and Doppler echocardiography was performed in all patients before admission to the study. There 
was no evidence of left ventricular hypertrophy, mitral valve prolapse, or any other structural heart disease. Global and regional left ventricular function was normal. Coronary arteriograms were completely normal.

\section{STUDY PROTOCOL}

The study was approved by the local research ethics committee and written informed consent was obtained from each patient before study entry. Antianginal medication was discontinued one week before enrolment, with the exception of short acting sublingual nitrates (none was administered in the six hours preceding exercise testing). Patients were asked to complete a formal, standardised chest pain questionnaire, and all underwent a complete physical examination, medical history, and urine and blood analyses (full blood count, urea, electrolytes, and liver function tests).

Patients were randomised in a double blind crossover fashion to receive either oral aminophylline 350 or $225 \mathrm{mg}$ twice daily (dosed according to body mass index and smoking habit) or oral placebo for three weeks. Blood samples for determination of the plasma aminophylline concentration were taken at the end of each three week period. Patients then underwent treadmill exercise testing using the modified Bruce protocol under standardised conditions. The end points for the test were $0.3 \mathrm{mV}$ horizontal or downsloping ST segment depression or progressive angina and fatigue. Twelve lead electrocardiograms and blood pressure measurements were obtained at baseline, at one minute intervals during exercise, and every minute during recovery. After signal averaging, the degree of ST segment depression was determined at 60 milliseconds after the J point in all 12 leads using a computer assisted system (CASE Marquette 12, Marquette Electronics Inc, Milwaukee, Wisconsin, USA). The lead showing maximum ST segment depression was selected for analysis. The duration of exercise, heart rate,

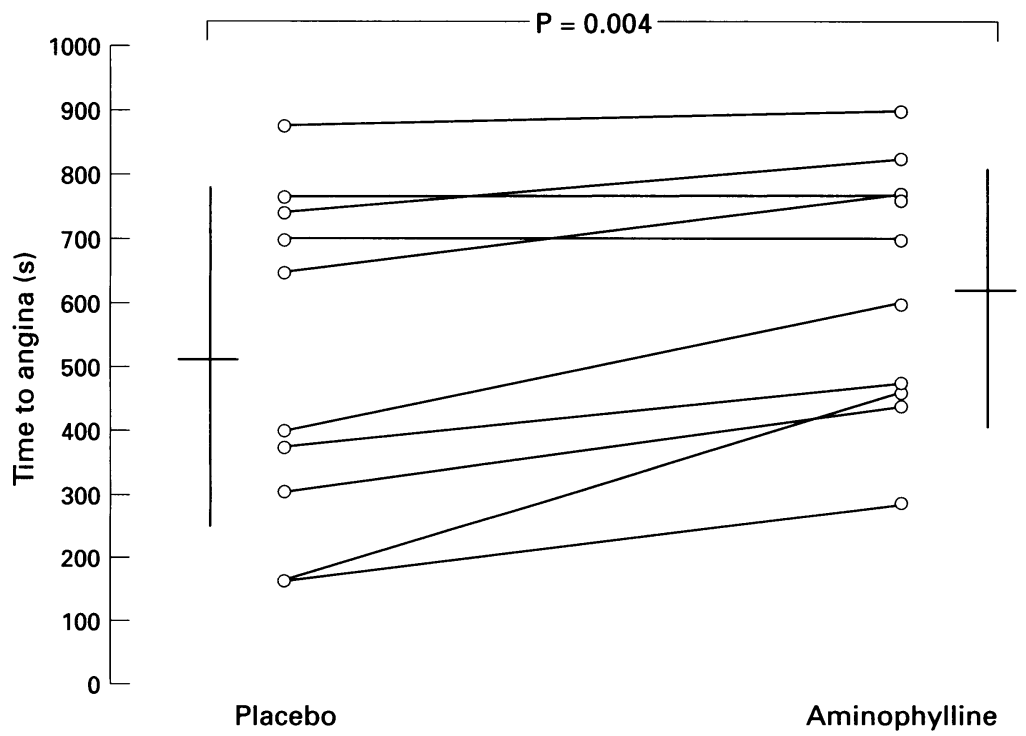

Figure 1 Individual patient data showing the effect of placebo and aminophylline on the time of angina onset during exercise testing (mean (1 SD)). and rate pressure product were measured at the onset of chest pain, peak exercise and, where appropriate, at $1 \mathrm{~mm}$ ST segment depression. The magnitude of ST segment depression at peak exercise and ST segment recovery time were also recorded. Exercise was followed by 48 hour ambulatory electrocardiographic monitoring using a two channel recorder and high quality pregelled electrodes (Marquette Electronics Inc). Leads V5 and V6 were used for monitoring. Magnetic tapes were analysed with a computerised system (Marquette Electronics Inc) by the same experienced technician. Episodes of significant ST depression $(0 \cdot 1 \mathrm{mV}$ horizontal or downsloping depression at $60 \mathrm{~ms}$ after the $\mathrm{J}$ point) were identified using a computer generated ST trend. An interval of one minute was required after the return of the ST segment to baseline before another discrete episode was counted. All electrocardiographic tracings and computer generated trends were reviewed by a second investigator blinded to patient treatment. Patients were asked to keep a detailed, standardised diary, noting the number and circumstances of all episodes of chest pain.

\section{STATISTICAL ANALYSIS}

Data are presented as means (SD). Quantitative variables were analysed by the two tailed Student's $t$ test for paired and unpaired values. A P value $<0.05$ was considered significant.

\section{Results}

EXERCISE TESTING

Three women withdrew from the trial while taking aminophylline, two because of side effects (nausea, palpitations). The mean (SD) plasma aminophylline concentration after three weeks' oral treatment in the remaining 10 patients was $11.0(4 \cdot 4) \mathrm{mg} / 1$.

All patients experienced chest pain during exercise. Treatment with aminophylline was associated with a significantly longer time to angina than with placebo (fig 1). Heart rate and rate pressure product at the onset of angina were also significantly greater in patients given aminophylline than in those who received placebo (table). ST segment depression at peak exercise was $0.1 \mathrm{mV}$ in eight patients administered placebo and in nine given aminophylline. Mean peak ST segment depression was not significantly different during treatment with aminophylline compared with that during placebo.

\section{ANGINA EPISODES AND AMBULATORY} MONITORING

The mean (SD) number of episodes of chest pain during the three week period was 18 (16) in patients given placebo and 11 (8) in those who received aminophylline ( $P=N S$ ) (fig 2 ). While receiving aminophylline, six patients reported a reduction in the number of episodes of chest pain, one reported no change, and three experienced a small increase.

Eight patients had good quality 48 hour 
Results of exercise testing during treatment with either placebo or aminophylline

\begin{tabular}{|c|c|c|c|}
\hline & $\begin{array}{l}\text { Placebo } \\
(n=10)\end{array}$ & $\begin{array}{l}\text { Aminophylline } \\
(n=10)\end{array}$ & $P$ \\
\hline Exercise time (s) & $765(188)$ & $798(149)$ & $0 \cdot 18$ \\
\hline Time to $1 \mathrm{~mm} \mathrm{ST} \mathrm{dep} \mathrm{(s)}$ & 719 (143) & $693(169)$ & 0.77 \\
\hline Time to angina (s) & $522(264)$ & $632(202)$ & 0.004 \\
\hline Recovery time (s) & $427(236)$ & $344(130)$ & 0.43 \\
\hline \multicolumn{4}{|l|}{ Baseline } \\
\hline Heart rate (beats/min) & $81(14)$ & $86(14)$ & $0 \cdot 38$ \\
\hline $\mathrm{SBP}(\mathrm{mm} \mathrm{Hg})$ & $120(17)$ & $118(17)$ & 0.72 \\
\hline $\mathrm{DBP}(\mathrm{mm} \mathrm{Hg})$ & $77(7)$ & $74(8 \cdot 0)$ & $0 \cdot 24$ \\
\hline RPP & $9718(1973)$ & $10172(2128)$ & 0.44 \\
\hline \multicolumn{4}{|l|}{$1 \mathrm{~mm} \mathrm{ST} \mathrm{dep}$} \\
\hline Heart rate (beats/min) & $134(8)$ & $139(16)$ & $0 \cdot 22$ \\
\hline $\mathrm{SBP}(\mathrm{mm} \mathrm{Hg})$ & $153(19)$ & $144(16)$ & $0 \cdot 16$ \\
\hline $\mathrm{DBP}(\mathrm{mm} \mathrm{Hg})$ & $75(9)$ & $76(7)$ & 0.63 \\
\hline RPP & $20416(2318)$ & $19909(2978)$ & 0.98 \\
\hline \multicolumn{4}{|l|}{ Angina } \\
\hline Heart rate (beats $/ \mathrm{min}$ ) & $118(15)$ & $135(19)$ & 0.002 \\
\hline $\mathrm{SBP}(\mathrm{mm} \mathrm{Hg})$ & $146(18)$ & $143(14)$ & 0.50 \\
\hline $\mathrm{DBP}(\mathrm{mm} \mathrm{Hg})$ & $74(8)$ & $78(10)$ & 0.09 \\
\hline ST dep $(\mathrm{mm})$ & $-0.4(0.4)$ & $-0.9(0.7)$ & 0.05 \\
\hline RPP & $17072(2361)$ & $19350(3431)$ & 0.03 \\
\hline \multicolumn{4}{|l|}{ Peak } \\
\hline Heart rate (beats/min) & $144(16)$ & $155(19)$ & 0.009 \\
\hline $\mathrm{SBP}(\mathrm{mm} \mathrm{Hg})$ & $161(19)$ & $159(20)$ & 0.61 \\
\hline $\mathrm{DBP}(\mathrm{mm} \mathrm{Hg})$ & $80(8)$ & $78(10)$ & 0.53 \\
\hline ST dep (mm) & $-1.5(0.8)$ & $-1.9(0.7)$ & $0 \cdot 17$ \\
\hline RPP & $22937(2865)$ & $24521(3807)$ & 0.06 \\
\hline \multicolumn{4}{|l|}{ Recovery } \\
\hline Heart rate (beats/min) & $79(9)$ & $91(9)$ & 0.009 \\
\hline $\mathrm{SBP}(\mathrm{mm} \mathrm{Hg})$ & $126(25)$ & $125(16)$ & 0.85 \\
\hline $\mathrm{DBP}(\mathrm{mm} \mathrm{Hg})$ & $73(10)$ & $73(6)$ & 0.85 \\
\hline RPP & 9909 (1819) & $11421(2242)$ & 0.01 \\
\hline
\end{tabular}

Values are means (SD).

SBP/DBP, systolic/diastolic blood pressure; RPP, systolic blood pressure/heart rate product; ST dep, ST segment depression.

\section{Discussion}

Treatment with aminophylline significantly increased the time to angina during exercise and reduced the number of chest pain episodes during daily life. Treatment was not associated with a significant improvement in the magnitude of ST segment depression at peak exercise or an increase in total exercise duration. The heart rate at the onset of angina, however, was significantly greater in patients who received aminophylline.

The potential of methylxanthines to improve symptoms in patients with angina is well recognised. ${ }^{14-20}$ Several workers ${ }^{14}{ }^{15}$ have suggested that, in patients with coronary artery disease, aminophylline prevents "myocardial steal" during stress by promoting a more favourable distribution of transmural myocardial blood flow. The relevance of this potential mechanism in patients with syndrome $\mathrm{X}$ is uncertain, however, as only a minority has evidence of impaired coronary flow reserve. ${ }^{24}$ Several studies have shown altered somatic and visceral pain perception in patients with syndrome $\mathrm{X},{ }^{8-11}$ raising the possibility that their angina is secondary to an exaggerated nociceptive response. The precise mechanisms underlying cardiac pain sensation are poorly understood, but there is growing evidence that adenosine may be the "metabolic messenger" responsible for its initiation. ${ }^{131-25}$ The delayed onset of exertional chest pain during treatment with an adenosine receptor blocker such as aminophylline in the present study, together with the earlier finding of heightened sensitivity to adenosine in patients with syndrome $\mathrm{X}^{26}$ supports the hypothesis that abnormal myocardial handling of this substance is important in this disorder. ${ }^{12}$

Previous studies have examined the effects of intravenous aminophylline in patients with syndrome X. Emdin et $a l^{16}$ found an increase in effort tolerance and abolition of "significant" ( $\geqslant 0.2 \mathrm{mV}$ ) ST segment changes following intravenous aminophylline in 12 patients with a history of dipyridamole induced chest pain responsive to aminophylline. In another study, Yoshio et $a l^{17}$ reported increased exercise duration and less exertional angina following aminophylline infusion in 12 patients. However, Inobe et al ${ }^{18}$ have recently shown that intravenous aminophylline improves ST segment depression only in patients with syndrome $\mathrm{X}$ who have reversible thallium-201 perfusion abnormalities. Heterogeneity in the response of patients with syndrome $\mathrm{X}$ to intravenous aminophylline may explain the disparate effects of oral aminophylline on chest pain and ST segment depression in the present study. The route of drug administration may also possibly influence the final clinical effect. The mechanism of chest pain and ST segment depression in syndrome $\mathrm{X}$ remain the subject of much debate, but it is conceivable that aminophylline blocks the final common pathway of cardiac pain sensation at the adenosine receptor without altering the initial pathological stimulus responsible for adenosine release and ST segment depression.

Figure 2 Number of episodes of chest pain reported by patients over a three week period while taking placebo or aminophylline tablets (mean (1 SD)). 


\section{LIMITATIONS}

The present investigation is limited by the small number of patients, the relatively high incidence of side effects $(23 \%)$, and the heterogenoeus response to aminophylline. These factors may indicate that the observed modest effect on angina threshold, while being of theoretical value, has no clinical significance. Nevertheless, while this may be true for patients with syndrome $\mathrm{X}$ considered collectively, the findings of this study suggest that a minority with this disorder may experience important clinical improvement, and further work designed to identify those who are most likely to respond to aminophylline is warranted.

We thank Napp Laboratories Ltd, Cambridge, UK, for generplacebo and aminophylline tablets for this study, Alison Redfern (Pharmacy at St George's Hospital, London) for contributing to the study design and dispensing of drugs, and Terry Lee (Analytical Unit, St George's Hospital Medical School) for determining the plasma aminophylline concentrations. PME is supported by a British Heart Foundation junior fellowship grant.

1 Kaski JC, Crea F, Nihoyannopoulos P, Hackett D, Maser A. Transient myocardial ischaemia during daily life in patients with syndrome X. Am $₹$ Cardiol 1986;58:1242-7.

2 Legrand V, Hodgson JM, Bates ER, Aueron FM, Mancin GB, Smith JS, et al. Abnormal coronary flow reserve and $\mathrm{GB}$, Smith JS, et al. Abnormal coronary flow reserve and radionuclide exercise test results in patients with normal

3 Cannon RO, Watson RM, Rosing DR, Epstein SE. Angina caused by reduced vasodilator reserve of the small corocaused by reduced vasodilator reserve of the small

4 Opherk D, Zebe H, Weihe E, Mall G, Durr C, Gravert B, et al. Reduced coronary dilatory capacity and ultrastructural changes of the myocardium in patients with angin pectoris but normal coronary arteriograms. Circulation 1981;63:817-25.

5 Cannon RO, Epstein SE. "Microvascular angina" as a cause of chest pain with angiographically normal coro-

6 Rosen SD, Uren NG, Kaski JC, Tousoulis D, Davies GJ, Camici PG. Coronary vasodilator reserve, pain perception and sex in patients with syndrome $X$. Circulation 1994;90:50-60.

7 Kaski JC, Rosano G, Nihoyannopoulos P, Collins P, Maseri A, Poole-Wilson PA. Cardiac syndrome X: clinical characteristics and left ventricular function. Long term follow up study. ₹ Am Coll Cardiol 1995;25:807-14.

8 Shapiro LM, Crake T, Poole-Wilson PA. Is altered cardiac sensation responsible for chest pain in patients with norsensation responsible for chest pain in patients with nor-
mal coronary arteries? Clinical observation during carmal coronary arteries? Clinical observation

9 Turiel M, Galassi AR, Glazier JJ, Kaski JC, Maseri A. Pain threshold and tolerance in women with syndrome $\mathrm{X}$ and women with stable angina pectoris. Am $\mathcal{F}$ Cardiol 1987;
60:503-7.

10 Cannon RO, Quyumi AA, Mincemoyer R, Stine AM, Gracely $\mathrm{RH}$, Smith WB, et al. Imipramine in patien with chest pain despite normal coronary angiograms. $N$ Engl F Med 1994;330:1411-7.

11 Chauhan A, Mullins PA, Thuraisingham SI, Taylor G, Petch MC, Schofield PM. Abnormal cardiac pain perception in syndrome X. F Am Coll Cardiol 1994;24: 329-35.

12 Maseri A, Crea F, Kaski JC, Crake T. Mechanisms of angina pectoris in syndrome X. F Am Coll Cardiol 1991; 17:499-506.

13 Sylven C. Mechanisms of pain in angina pectoris - a critical review of the adenosine hypothesis. Cardiovasc Drugs Ther 1993;7:745-59.

14 Picano E, Pogliani M, Lattanzi F, Distante A, L'Abbate A Exercise capacity after acute aminophylline administration in angina pectoris. Am 7 Cardiol 1989;63:14-16

15 Crea F, Pupita G, Galassi AR, El-Tamimi H, Kaski JC Davies GJ, et al. Comparative effects of theophylline and isosorbide dinitrate on exercise capacity in stable angina pectoris, and their mechanisms of action. Am $\mathcal{F}$ Cardiol 1989;64:1098-102.

16 Emdin M, Picano E, Lattanzi F, L'Abbate A. Improved exercise capacity with acute aminophylline administration in patients with syndrome X. $\mathscr{F} \mathrm{Am}$ Coll Cardiol 989;14:1450-3

17 Yoshio H, Shimizu M, Kita Y, Ino H, Kaku B, Taki J, et al. Effects of short-term aminophylline administration on cardiac functional reserve in patients with syndrome $\mathrm{X}$. Am Coll Cardiol 1995;25:1547-51.

18 Inobe Y, Kugiyama K, Morita E, Kawano H, Okumura K, Tomiguchi S, et al. Role of adenosine in pathogenesis of syndrome $\mathrm{X}$ : assessment with coronary hemodynamic measurements and thallium-201 myocardial single-phomeasurements and thath tom 1996;28:890-6.

19 Crea F, Pupita G, Galassi A, El-Tamimi H, Kaski JC, Davies G, et al. Role of adenosine in pathogenesis of anginal pain. Circulation 1990;81:164-72.

20 Heller GV, Barbour MM, Dweik RB, Corning JJ, McClellan JR, Garber CE. Effects of intravenous theophylline on exercise-induced myocardial ischemia. I. phyline on exercise-induced myocardial ischemia. Impact on the isch

21 Sylven C, Beermann B, Jonzon B, Brandt R. Angina pectoris-like pain provoked by intravenous adenosine in healthy volunteers. $B M \Im$ 1986;293:227-30

22 Sylven C, Jonzon B, Brandt R, Beermann B. Adenosineprovoked angina pectoris-like pain-time characteristics, nfluence of autonomic blockade and naloxone. Eur Heart F 1987;8:738-43.

23 Sylven C, Jonzon B, Edlund A. Angina pectoris-like pain provoked by i.v. bolus of adenosine: relationship to coronary sinus blood flow, heart rate and blood pressure in healthy volunteers. Eur Heart f 1989;10:48-54.

24 Lagerqvist B, Sylven C, Beermann B, Helmius G, Waldenström $A$. Intracoronary adenosine causes angina pectoris like pain - an inquiry into the nature of visceral pain. Cardiovasc Res 1990;24:609-13.

25 Thames MD, Kinugawa T, Dibner-Dunlap ME. Reflex sympathoexcitation by cardiac sympathetic afferents during myocardial ischemia. Role of adenosine. Circulation ing myocardial isch

26 Lagerqvist B, Sylven C, Waldenström A. Low threshold for adenosine induced chest pain in patients with angina pectoris and normal coronary angiogram. Br Heart $\mathrm{f}$ 1992; 68:282-3. 